\title{
Development and Testing of a New Tillage Apparatus.
}

\begin{abstract}
Disk plow combined with rotary blades, defined as Comboplow, is used for soil preparation for planting. A multiple tillage operation is reduced in a single pass resulting in a potential reduction of soil compaction, labor, fuel cost and saving in time. The Comboplow was tested at University Putra Malaysia Research Park, Serdang, Selangor, Malaysia, on three different plots of $675 \mathrm{~m} 2$ in the year 2010/2011.The treatments were three types of blades [(straight (S), curved (c) and L-shaped)] and three rotary speeds (130,147 and $165 \mathrm{rpm})$. The parameters were Mean Weight Diameter Dry Basis (MWDd), Mean weight Diameter Wet Basis (MWDw), and Aggregate Instability Index (II). Result showed that an increase in the rotational speed from 130 to $165 \mathrm{rpm}$ decreased the mean weight diameter (wet basis), mean weight diameter (dry basis) and instability index.
\end{abstract}

Keyword: Tillage Operation; Combined Implement; Disk Plow; Rotary Blade; Mean Weight Diameter; Stability Index 